\title{
Laboreal
}

Volume $10 \mathrm{~N}^{\circ} 2$ | 2014

Análise ergonómica do trabalho e formação - Parte II

\section{Un espejo deformante: apuntes históricos sobre la construcción jurídica de las enfermedades profesionales en Bélgica}

Um espelho deformante: notas históricas sobre a construção jurídica das doenças profissionais na Bélgica

Un miroir déformant : notes historiques sur la construction juridique des maladies professionnelles en Belgique

A distorting mirror: notes for the history of occupational disease legislation in Belgium

\section{Laurent Vogel}

\section{OpenEdition}

\section{Journals}

Edición electrónica

URL: http://journals.openedition.org/laboreal/4625

DOI: $10.4000 /$ laboreal. 4625

ISSN: 1646-5237

Editor

Universidade do Porto

Referencia electrónica

Laurent Vogel, « Un espejo deformante: apuntes históricos sobre la construcción jurídica de las enfermedades profesionales en Bélgica », Laboreal [En línea], Volume 10 №2 | 2014, Publicado el 01 diciembre 2014, consultado el 07 octubre 2019. URL : http://journals.openedition.org/laboreal/4625 DOI : 10.4000/laboreal.4625

Este documento fue generado automáticamente el 7 octubre 2019.

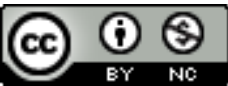

Laboreal está licenciado com uma Licença Creative Commons - Atribuição-NãoComercial 4.0 Internacional. 


\section{Un espejo deformante: apuntes históricos sobre la construcción}

\section{jurídica de las enfermedades profesionales en Bélgica}

Um espelho deformante: notas históricas sobre a construção jurídica das doenças profissionais na Bélgica

Un miroir déformant : notes historiques sur la construction juridique des maladies professionnelles en Belgique

A distorting mirror: notes for the history of occupational disease legislation in Belgium

\section{Laurent Vogel}

\section{NOTA DEL EDITOR}

http://dx.doi.org/10.15667/laborealx0214lv

Manuscrito recibido en: enero/2014

Aceptado tras peritaje: noviembre/2014

\section{Introducción}

1 El reconocimiento de las enfermedades profesionales permite a las víctimas obtener una compensación. Dicho reconocimiento ejerce también una función colectiva. La indemnización hace que determinados daños a la salud adquieran mayor visibilidad. Este reconocimiento social influye en el conjunto de los actores del campo de la salud en el trabajo. 
2 Los sistemas para el reconocimiento de las enfermedades profesionales se asimilan a un conjunto de filtros de diferentes naturalezas, es decir, filtros conceptuales, refiriéndose a la definición misma de una relación de causalidad entre el trabajo y las patologías; institucionales, jurídicos, sociales y culturales. El efecto combinado de estos filtros va más allá de lo puramente cuantitativo. Los datos que se obtienen a través de ellos distan mucho de ser representativos, en formato reducido, de la realidad general. Dichos datos presentan una imagen reflejada en un espejo deformante, de suerte que los casos de cáncer o los problemas de salud mental quedan reducidos a una mayor invisibilidad. Algunos grupos sociales, como trabajadores precarizados o inmigrantes, están en zonas grises. La discriminación contra las mujeres es una de las formas más comunes de este efecto deformante.

3 La historia social del reconocimiento de las enfermedades profesionales en Bélgica aún está por escribirse. Sobre la silicosis se han hecho estudios indiscutiblemente interesantes que plantean el problema de la relación entre el derecho y los conocimientos médicos (Geerkens, 2009; 2014; IHOES, 1998). Los debates en torno a la silicosis que se desarrollaron entre inicios del siglo XX y los años 60 constituyen, en numerosos aspectos, una "historia que no pasa" ni en el análisis jurídico ni en la historia médica de la salud en el trabajo. A partir del momento en que la silicosis fue reconocida como enfermedad profesional quedó en el olvido la abundante producción científica belga que se negaba a admitir ese carácter de la enfermedad. Los autores que más se dedicaron a esta investigación pasaron a ocuparse de otros temas de estudio, mientras que los juristas se limitaron a describir la nueva situación del derecho positivo, satisfechos, al parecer, con esta nueva prueba del carácter avanzado de la legislación social.

4 El atraso de la legislación belga en lo que respecta a la silicosis constituye un caso extremo, si bien es un claro indicio de una tendencia más profunda. El mesotelioma, enfermedad provocada por el amianto, pasó a formar parte de la lista belga en 1982, cuando en el Reino Unido esta enfermedad había sido reconocida en 1966. El inmenso desfasaje que existe entre el objetivo declarado de indemnizar las enfermedades profesionales y la realidad de una aplicación sumamente restrictiva, ceñida a un número limitado de patologías, justifica que se examine de manera crítica la elaboración de las normas.

5 En los Estados Unidos, este tema ha llamado la atención de algunos investigadores que realizan estudios de carácter general o bien enfocadas sobre casos concretos como las enfermedades respiratorias de los mineros o los trastornos músculo-esqueléticos. En Francia, el renacimiento de la historiografía sobre la salud en el trabajo se enmarca en un contexto en el que el escándalo provocado por el amianto ha jugado un papel decisivo en la evolución del derecho y de las ciencias sociales en materia de salud en el trabajo. En Bélgica el desinterés es flagrante, y salvo un trabajo minucioso sobre la historia de la silicosis realizado por Eric Geerkens, nunca se ha emprendido una investigación sistemática sobre la elaboración de un marco jurídico para las enfermedades profesionales y su negociación política.

6 Sin embargo, tanto para el historiador de las sociedades contemporáneas como para el jurista, esta es una materia apasionante, tal y como lo demuestran los trabajos de Katherine Lippel en Quebec (Lippel, 2003; Lippel \& Cox, 2012; Lippel \& Lefebvre, 2014). El derecho en materia de enfermedades profesionales se presenta como reglamentario, laborioso y técnico, pero tras esta apariencia se esconden cuestiones jurídicas de 
considerable importancia. Un análisis histórico ayuda a comprender el planteo, a través de este derecho, de una contradicción fundamental del trabajo asalariado, formulada en los siguientes términos por Alain Supiot (1994, p. 68): “A diferencia del empleador, en la relación laboral el trabajador no pone en riesgo su patrimonio sino su pellejo y precisamente -para ponerlo a salvo- fue que se constituyó el derecho del trabajo" (traducción libre).

7 La legislación y la jurisprudencia relativas a las enfermedades profesionales plantean constantemente la pregunta no sólo acerca del recurso, a menudo ambiguo y a veces excesivo, al lenguaje y a los conocimientos de las disciplinas sanitarias, sino también sobre el papel positivo que juegan dichas disciplinas al examinar la pertinencia de las normas jurídicas.

El presente artículo describe la aparición de la legislación sobre las enfermedades profesionales y analiza una contradicción aparentemente absurda: Bélgica fue uno de los últimos países del mundo en reconocer la silicosis como enfermedad profesional a pesar de que contaba con una industria minera importante. Para entender dicha contradicción, este artículo propone una interpretación basada en la interacción entre la historia social de los conocimientos médicos, el desarrollo de la normativa jurídica y algunas peculiaridades de la historia de las relaciones colectivas de trabajo en Bélgica. El artículo examina en una primera sección la evolución del derecho en materia de prevención de riesgos profesionales. En una segunda sección, analiza la evolución de la normativa sobre la indemnización de las enfermedades profesionales concentrándose en la investigación de las causas del tardío reconocimiento de la silicosis.

\section{Evolución del derecho en materia de prevención}

\subsection{Desde Ramazzini hasta la legislación industrial}

El impacto negativo del trabajo en la salud ha sido objeto de múltiples observaciones a lo largo de la historia. Dicho impacto no es consecuencia únicamente de las condiciones materiales de la producción (equipos, sustancias químicas, etc...), pues también está determinado por las relaciones sociales. La división del trabajo no se limita a un reparto funcional y técnico de las tareas según las capacidades propias de cada individuo. También tiene una dimensión social, colectiva, y es la principal fuente de desigualdades de género y de clase. En otras sociedades, la división del trabajo fue un elemento esencial para establecer el estatus de las castas o la demarcación entre hombres libres y esclavos. Entre las desigualdades, las desigualdades sociales de la salud ocupan un lugar importante. Éstas se subestiman y a veces se legitiman a través de mecanismos diversos, a saber, la naturalización (cuando la desigualdad se atribuye a la biología, ya sea en referencia a las mujeres, las "razas inferiores" o la idea de que las patologías causadas por el trabajo son producto simplemente del envejecimiento "natural" de la población), las ideologías del progreso (según las cuales el crecimiento de los recursos materiales va acompañado de algunos sacrificios legítimos) o una individualización de los procesos patógenos, que se centra en los factores individuales cuando se trata de determinantes colectivos, como las condiciones de trabajo.

Bernardino Ramazzini había planteado, desde antes de la primera revolución industrial, a través de su libro "De morbis artificum diatriba", un enfoque general sobre este tema. Este libro se editó por primera vez en Módena en el año 1700. Se estuvo traduciendo y 
reeditando con regularidad en el curso de los últimos tres siglos. El libro se basa en observaciones clínicas y en una escucha de la percepción que diferentes profesiones tenían sobre la relación entre las enfermedades y sus actividades laborales. Ramazzini describe algunas enfermedades laborales situándolas en un contexto preindustrial. Aun cuando su marco de explicación etiológica es anticuado, muchas de sus conclusiones siguen siendo pertinentes para comprender la relación entre el trabajo y la salud. Su lectura en el presente muestra que nos podemos equivocar sobre la causalidad científica y al mismo tiempo captar de manera intuitiva la causalidad social. El prefacio de su libro sigue siendo de actualidad: "Son muchas las cosas que el médico, al atender a un enfermo, debe tratar de averiguar, bien sea a través del mismo paciente, bien a través de los que le atienden, siguiendo las normas del Divino Preceptor: "Cuando estés ante un enfermo, conviene que le preguntes qué le duele, cuál es el motivo, desde hace cuántos días, si hace de vientre y qué alimentos toma". Palabras son éstas de Hipócrates en su libro De las afecciones; permítaseme añadir también esta pregunta: "y qué oficio desempeña". Aunque esta pregunta pueda referirse a las causas ocasionales de la enfermedad, considero muy oportuno - es más, necesario - no dejarla en olvido, especialmente cuando se trate a una persona de condición humilde; y esto compruebo que, en la práctica, se observa en muy contadas ocasiones o que es tenido muy poco en cuenta en caso de que así le conste al médico, por otra parte, a la hora de aplicar la curación, cuando su cumplimiento es de vital importancia si se quiere conseguir un éxito mayor en la curación" ( Ramazzini, 2012, p. 13).

La producción de conocimientos sobre las enfermedades medioambientales en el contexto de grandes aglomeraciones urbanas y del auge de la industria ha sido escasa y puntual. Se relacionaba con los intentos de reglamentación de la contaminación industrial iniciados bajo el antiguo Régimen. Tales intentos desembocaron tras la revolución industrial en la adopción de textos que durante casi dos siglos dieron fundamento legal a la reglamentación belga en materia de salud y seguridad en el trabajo [1] constituida por la Ley del 21 de abril de 1810 que establece el régimen de minas y canteras y por el decreto del 15 de octubre de 1810 sobre el régimen de los establecimientos clasificados. De estos textos jurídicos derivó durante todo el siglo XIX la legislación industrial, actualmente dividida entre la legislación medioambiental y la legislación sobre bienestar en el trabajo.

El peritaje médico se incluye dentro de esta actividad de reglamentación. Son numerosos los médicos cuya opinión se consulta en los procedimientos de autorización de los establecimientos clasificados. Este primer acercamiento entre el peritaje médico y los conceptos jurídicos implica un cambio de perspectiva para la formación del conocimiento experto. Determina la manera de plantear las preguntas, condicionando las respuestas proporcionadas. Como lo destaca Bernard-Pierre Lécuyer, "La intervención del médico higienista se basa la responsabilidad de tutela que tiene el poder público sobre las actividades industriales y su primera preocupación no consiste tanto en proteger la salud de los trabajadores que ejercen su actividad dentro de los establecimientos como en garantizar que dicha actividad no tenga consecuencias negativas para el entorno" (Lécuyer, 1983, pp. 49-50, traducción libre). Este tipo de intervención tiene entonces tendencia a subestimar los riesgos inherentes a las condiciones de trabajo. Una prueba de ello es el peritaje realizado por ParentDuchâtelet y d'Arcet, publicado en 1829, sobre la salud en las fábricas de tabaco: "estos hombres, si bien es cierto que están flacos (...) no están amarillos ni descoloridos (...). Contemplando la masa de trabajadores: hombres, mujeres y niños, todos denotan estar 
en buena salud (...) entre ellos se distingue una que otra cara pálida, pero no son más numerosas que en otros lugares". En su descripción de las fábricas de tabaco en Lille, señalan que "Las principales enfermedades que padecen los obreros dedicados a la fabricación de tabaco son las irritaciones crónicas de los órganos de los sistemas respiratorio y digestivo (...). Sin negar la influencia que puede tener el tabaco en la aparición de estas enfermedades, debemos reconocer que es de carácter muy leve" (cit in Lécuyer, 1983, pp. 57-58, traducción libre).

\subsection{Desde las investigaciones de Ducpétiaux hasta el nacimiento del derecho del trabajo en Bélgica}

13 La explotación intensiva de las primeras generaciones de trabajadores de la revolución industrial tuvo consecuencias catastróficas para la salud. Relatos, encuestas y testimonios del siglo XIX coinciden en describir a los obreros de la época como seres cuyo primer rasgo distintivo eran los daños a la integridad física provocados por el trabajo. Las relaciones sociales dejan su huella en los cuerpos de los trabajadores: rostros pálidos, problemas de crecimiento en los niños, respiración dificultosa, envejecimiento precoz, numerosos mutilados, etc. La situación de las mujeres fue descrita de manera extensa en los estudios sobre las condiciones de trabajo que se llevaron a cabo en el siglo XIX, pero algunas actividades siguieron ignorándose. La información que se tiene sobre las trabajadoras domésticas es sumamente escasa. Las encuestas conceden menos el uso de la palabra a las obreras que a los obreros; a éstas se las analiza en lo que respecta a sus cuerpos, su moralidad o su comportamiento, pero no se las interroga sobre su salud o sus condiciones de trabajo. Los textos de Flora Tristán constituyen una excepción significativa. En casos extremos, el conocimiento médico retoma son jerga erudita fantasías masculinas. Tal el caso de los estudios sobre onanismo entre las obreras que trabajaban con máquinas de coser.

En 1843, se creó en Bélgica una Comisión a instancias del Ministro del Interior, JeanBaptiste Nothomb. Esta Comisión, dirigida por Édouard Ducpétiaux, inspector general de prisiones y establecimientos de beneficencia, se dedicó a investigar sobre las "condiciones de las clases obreras y sobre el trabajo de los niños". Los trabajos de la Comisión fueron publicados en 1846 y 1848 [²].

El informe de esta Comisión sigue siendo una referencia indispensable sobre las condiciones de trabajo en esa época. La metodología aplicada se caracterizó sin embargo por excluir una fuente de información importante. Se elaboraron cuatro cuestionarios diferentes para sondear la opinión de los dirigentes industriales, las cámaras de comercio e industria, las sociedades médicas y los consejos de salubridad pública [3]. Se recogieron así testimonios sobre el mundo del trabajo visto desde arriba o desde afuera. Además de lo que expresa este estudio -cuya lectura sigue siendo apasionante- también contribuye a establecer el estatus de experto. La exclusión del conocimiento obrero sorprende cuando se sabe que en algunas encuestas realizadas en otros países en la misma época los investigadores interrogaban a los obreros sobre sus condiciones de vida y de trabajo [4].

16 La Comisión elaboró un proyecto de ley en el que planteaba limitar la duración del tiempo de trabajo de los adultos a 12 horas y 30 minutos por jornada. Además proponía prohibir el trabajo de los niños menores de diez años en la industria (con una exención que permitía seguir empleando a los niños que ya estuviesen trabajando antes de la 
promulgación de la ley), limitar a 6 horas y 30 minutos la duración del trabajo diario de los jóvenes con edades comprendidas entre 10 y 14 años, y a 10 horas y 30 minutos la jornada de los jóvenes trabajadores con edades entre 14 y 18 años. El trabajo de las mujeres en las minas abiertas y subterráneas ya no se permitiría. En lo que respecta a las medidas de prevención aplicables a los obreros adultos, el proyecto prescribía una obligación general que deberían cumplir los directores de establecimientos industriales. Éstos "debían acatar todas las normas de seguridad y salubridad en sus explotaciones. Debían velar por el mantenimiento del orden y las buenas costumbres en sus talleres y, particularmente, por la conservación de la salud, la educación y la instrucción de sus obreros jóvenes". De la definición de normas más precisas se ocuparían los textos reglamentarios. Todas estas propuestas fueron rechazadas por el Parlamento.

Las investigaciones sobre las condiciones de vida de la clase obrera, realizadas tanto en Bélgica como en Francia durante la primera mitad del siglo XIX, mostraban grandes divergencias en la comunidad médica. Si bien es cierto que estas divergencias reflejaban en parte orientaciones político-sociales opuestas que se observaban entre los juristas y los políticos, o dentro del patronato, también es cierto que las mismas conservaban una especificidad que tiene que ver con la construcción social de las ciencias. De manera sintética, se puede considerar que los conocimientos médicos se dividían en tres perspectivas diferentes.

1. Había una corriente que negaba los efectos nocivos de la industrialización sobre la salud. Según ella, los trabajadores activos tenían por lo general buena salud [5]. Algunas profesiones obreras tenían incluso un efecto benéfico para la salud. La corriente concluía que las críticas dirigidas en contra de las condiciones de trabajo se regían por la pasión ideológica. Dicha corriente ponía de relieve una objeción invocada con frecuencia para oponerse a la legislación sobre la salud en el trabajo. Ante exigencias reglamentarias precisas, el patronato podría decidir el cierre de las empresas. El impacto sanitario del pauperismo era aún más dramático que el de las condiciones de trabajo.

2. Había una segunda corriente enfocada sobre las condiciones de vida fuera del trabajo: insalubridad de las viviendas, mala alimentación, moralidad deficiente, imprevisión ante los riesgos, higiene deplorable, alcoholismo, degeneración de la raza, etc... Esta corriente ocupaba un lugar preponderante en el desarrollo de la higiene social. No negaba los efectos del trabajo sobre algunos de estos factores, como consecuencia del trabajo de los niños, la promiscuidad en los talleres o las minas, las largas jornadas de trabajo o los bajos salarios (también se emplea el argumento inverso, según el cual el recrudecimiento del alcoholismo y el debilitamiento de la moral serían producto de salarios demasiado altos y del acortamiento de la jornada laboral). De manera general, esta corriente consideraba de manera negativa el trabajo de las mujeres en la industria y las minas. Más que a través del trabajo, la condición de vida de la clase obrera se concebía dentro de un enfoque amplio de biología social en el que los pobres constituían al mismo tiempo una clase peligrosa y una clase puesta en peligro.

3. La tercera corriente hacía énfasis en el efecto de las condiciones de trabajo: vapores, humos y polvos tóxicos, máquinas peligrosas, gestos repetitivos y esfuerzos físicos excesivos. Esta corriente está vinculada con la higiene industrial. En relación con la época de Ramazzini, el enfoque según las profesiones se completa por medio de un análisis basado en algunos factores de nocividad que no dependen necesariamente de las profesiones ejercidas.

18 Aun cuando la primera corriente podía estar condicionada por la posición política y social de una parte importante de la comunidad médica, las divergencias entre las dos otras corrientes se desarrollaban de manera bastante autónoma con respecto al 
compromiso político de los médicos. Se podía estar a favor de cambios sociales radicales o, por el contrario, predicar la moderación tanto entre los higienistas sociales como entre los higienistas industriales. Asimismo, había divergencias considerables según que las enfermedades se atribuyesen al efecto de sustancias tóxicas o al desgaste provocado por el trabajo. Los defensores de la higiene social solían tener en cuenta este último factor, pues comprobaban el daño causado por el esfuerzo excesivo, el trabajo monótono y repetitivo, la inmovilidad forzada de ciertas partes del cuerpo, etc. Allí radica, según nuestra opinión, la diferencia principal que existía entre la percepción erudita y los conocimientos obreros sobre la salud en el trabajo. Estos últimos tendían más bien a aplicar un enfoque global sin separar los riesgos tóxicos y la organización del trabajo. El impacto global del trabajo en la salud es sin embargo difícil de evaluar empleando métodos experimentales y cuantitativos. Dicho impacto puede manifestarse de manera más directa a través de la percepción subjetiva, especialmente cuando ésta se enmarca en una movilización colectiva.

19 A los trabajos de la Comisión de 1843 no se les dio seguimiento desde el punto de vista legislativo. La cuestión obrera siguió siendo objeto de informes dramáticos que no modificaron la posición del legislador de negarse a intervenir en el ámbito social. No faltaron los argumentos jurídicos que consideraban que establecer una reglamentación del trabajo equivaldría a una injerencia inaceptable del Estado. En 1869, el dirigente liberal Frère-Orban hacía referencia a la antinomia que existía entre una reglamentación del trabajo y el derecho de familia: "Una ley sobre el trabajo de los niños es una ley que priva en masa a los padres de familia de las clases trabajadoras de la tutela natural y legitima de sus hijos; es una ley que declara que éstos no son ni dignos ni aptos para ejercer correctamente dicha tutela; es una ley que proclama que, en las clases obreras, los padres no tienen corazón ni las madres entrañas" (Chlepner, 1972, p. 101, traducción libre).

Bélgica ha sido el último país industrializado de Europa en adoptar una legislación específica relativa a las condiciones de trabajo. Entre 1831 y 1887, las normas jurídicas que se aplicaban consistían principalmente en normas de actuación policial destinadas a imponer disciplina en el trabajo y reprimir las formas de acción colectiva del movimiento obrero (cartilla de trabajo, represión del vagabundeo, prohibición de formar coaliciones, etc.). Según Devinck, la represión de las coaliciones pudo haber sido utilizada directamente para combatir las prácticas obreras destinadas a proteger la salud. Es lo que se desprende de un juicio que se produjo en Francia en 1833que involucró a varios obreros fundidores. Éstos interrumpían colectivamente el trabajo para salir del taller y cambiar de aire, acogiéndose de esta forma a una práctica establecida para proteger la salud del obrero "debido a las tareas pesadas e insalubres a las que éste se dedica, trabajando en talleres con una atmósfera cargada de polvo y gas nocivo que el mismo respira continuamente, y porque el calor de las estufas y los hornos, cuya temperatura se aumenta a un grado muy alto, es excesiva" (Devinck, 2010, p. 75, traducción libre).

21 La única intervención reglamentaria posible contra los riesgos del trabajo se situaba en el marco de la legislación relativa a los establecimientos clasificados. A partir de 1849, se estableció que los procedimientos de autorización contemplarían una serie de criterios relativos a la seguridad y la higiene de los trabajadores. El 28 de abril de 1884, basándose en la policía de minas, se adoptó el primer texto de Bélgica como nación 
independiente por el que se limitaba el trabajo subterráneo en las minas a los chicos de doce años y a las chicas de catorce años de edad.

Tras los disturbios obreros que sacudieron Bélgica en marzo de 1886, el poder legislativo salió de su letargo. La primera medida fue crear una Comisión de Investigación sobre el trabajo industrial presidida por Eudore Pirmez, quien era al mismo tiempo un industrial y un parlamentario liberal. La Comisión publicó un informe voluminoso en 1888. El Parlamento ya no podía seguir eludiendo el tema y se vio obligado a debatir sobre varios proyectos de ley que le fueron presentados.

En lo que concierne a la salud en el trabajo, la primera ley fue la promulgada el 31 de diciembre de 1889, relativa al trabajo de los niños y las mujeres; una ley que contempla al mismo tiempo la protección y la discriminación. Su objetivo era alejar a las mujeres de determinadas situaciones peligrosas (para ellas o para su progenitura) en lugar de eliminar los riesgos. Esta ley prohíbe utilizar a los niños menores de doce años para el trabajo industrial y limita la duración de la jornada laboral a doce horas en lo que respecta a los jóvenes de 12 a 16 años de edad y las jóvenes de 12 a 21 años de edad. La referida ley prohíbe emplear mujeres menores de 21 años para realizar trabajos subterráneos en las minas. También prohíbe emplear mujeres durante cuatro semanas después que éstas hayan dado a luz, pero la ausencia total de garantías en cuanto a la remuneración resta eficacia a la medida.

\subsection{Desde la ley de 1889 hasta la ley de 1996 relativa al bienestar en el trabajo}

El marco legislativo relativo a la prevención ha evolucionado de manera considerable desde 1889. Cabe recordar la ley de 10 de marzo de 1900 relativa al contrato de trabajo, por la que se estipula una obligación general en materia de seguridad que el empleador debe cumplir. Los parlamentarios evocaron en este contexto la posibilidad de redactar un código del trabajo en el cual se desarrollarían los diferentes aspectos de la ley. Esta propuesta fue frenada por la adopción de la ley relativa a la indemnización de los accidentes de trabajo, promulgada el 24 de diciembre de 1903. La indemnización de estos accidentes colocó en segundo plano la política de prevención durante cerca de tres cuartos de siglo. La adopción de la ley relativa a la indemnización de tres enfermedades profesionales, promulgada el 27 de julio de 1927, jugó un papel similar, frenando el desarrollo de una política de prevención más eficaz.

En el contexto de las reformas sociales posteriores a la Segunda Guerra Mundial, se reformó, más en la forma que en el fondo, la legislación relativa a la salud laboral y se procedió a una codificación ilusoria. El texto principal en materia de salud y seguridad fue el Reglamento General para la Protección en el Trabajo (RGPT). Este texto, voluminoso y disparatado, que se adoptó entre 1946 y 1948, se limitaba en realidad a agrupar sin reflexión crítica un conjunto de textos reglamentarios anteriores. El fundamento legal de las disposiciones reglamentarias del RGPT seguía repartido en una decena de leyes fundamentales de naturaleza bastante heterogénea, a las que se añadió la ley de 10 de junio de 1952 relativa a la salud y la seguridad de los trabajadores, así como a la salubridad del trabajo y de los sitios de trabajo.

Las disposiciones del RGPT fueron revisadas en múltiples ocasiones. El hecho de que no se dispusiese de un plan de conjunto y de que existieran al mismo tiempo normas fundamentales y disposiciones particulares restaba mucha legibilidad al RGPT. Estas 
características reforzaban los prejuicios de numerosos juristas, para quienes la legislación sobre la salud en el trabajo no constituía más que una materia puramente técnica, desprovista de principios jurídicos y raramente sujeta a debates doctrinales.

No cabía duda de que la materia exigía una reforma, pero la voluntad a nivel político era frenada por una larga tradición de inmovilismo donde se mezclaban un enfoque técnico o administrativo y la búsqueda paralizante de un consenso entre las organizaciones sindicales y patronales. Cada cambio parcial del marco legislativo ha estado relacionado con movilizaciones sociales importantes, a saber, la instauración de los comités de seguridad e higiene y el desarrollo de la medicina laboral durante los años siguientes a la catástrofe minera de Marcinelle en 1956, la orientación hacia una prevención primaria y una mayor atención a las sustancias tóxicas en el contexto de la fuerte conflictividad social que marcó el periodo posterior a 1968.

Fue necesaria la contribución decisiva de las directivas de la Comunidad Europea para superar estos obstáculos e incluir en la agenda una reforma general que tuvo como elemento principal la ley relativa al bienestar en el trabajo, promulgada el 4 de agosto de 1996. Se trataba de una reforma global. Resulta paradójico que esta reforma no se haya combinado con una reforma similar del sistema de indemnización de los riesgos profesionales, que sigue funcionando como un freno de la prevención primaria y que brinda inmunidad casi total a los empleadores en materia de responsabilidad civil cuando la falta de prevención origina accidentes o enfermedades.

\section{Evolución de la indemnización de las enfermedades profesionales}

Los riesgos del trabajo han sido determinantes para la crítica del enfoque civilista de las relaciones laborales. La jurisprudencia que predominó durante la primera mitad del siglo XIX tendía a excluir cualquier indemnización de accidentes o enfermedades basada en la responsabilidad civil del empleador. Según ésta jurisprudencia, cuando el trabajador manifestaba su acuerdo con las condiciones del "contrato de arrendamiento de servicios", eso significaba que conocía y aceptaba los riesgos inherentes a su actividad profesional. En los últimos decenios del mismo siglo, se produjo una evolución jurisprudencial que terminó reconociendo, aunque con ciertas objeciones, la existencia de una obligación patronal en materia de seguridad. El incumplimiento de esta obligación daría lugar a una indemnización por daños en el ámbito del derecho común de la responsabilidad civil, pero la carga de la prueba recaería en la víctima. Los litigios se referían casi exclusivamente a accidentes de trabajo. El legislador terminó dictando el 10 de marzo de 1900 una ley sobre la obligación general de garantizar la seguridad, por la cual se imponía al empleador "velar, con la diligencia de un buen padre de familia, y no obstante cualquier acuerdo en contrario, para que el trabajo se realice en condiciones adecuadas desde el punto de vista de la seguridad y la salud del obrero y que, en caso de accidente, se le preste a éste los primeros auxilios". Quedaba así establecida la responsabilidad contractual del empleador en caso de accidente o enfermedad causados por el trabajo. Pero seguía planteándose un inconveniente significativo, ya que los trabajadores que eran víctimas de algún accidente de trabajo o de una enfermedad profesional tenían que pasar por procedimientos judiciales a fin de obtener una indemnización en un contexto en el que cualquier incapacidad de trabajo era sinónimo de miseria material extrema y marginalización social. 


\subsection{La ley del 24 de diciembre de 1903 sobre accidentes laborales} cabo en varias etapas. Respecto a otros países industrializados, Bélgica quedó un tanto rezagada en la adopción de leyes. En 1890, Paul Janson y otros diputados de la izquierda liberal presentaron un proyecto de ley por el que se establecía un seguro obligatorio de los empleadores contra los accidentes laborales y las enfermedades profesionales; proyecto que fue rechazado. El Parlamento se limitó a asignar fondos públicos para ayudar a la creación de un Fondo de Previsión y Asistencia. A principios del siglo XX, la evolución legislativa de los países vecinos no dejó más opción a Bélgica que aprobar una legislación sobre el seguro obligatorio ante riesgos profesionales. La primera ley relativa a los accidentes laborales se votó el 24 de diciembre de 1903. Esta ley excluía las enfermedades profesionales de su ámbito de aplicación.

hacerse preguntas sobre la pertinencia de esta exclusión que, en derecho belga, sigue estableciendo una clara distinción entre dos regímenes reguladores y dos ramas separadas de la seguridad social. El Convenio $n^{\circ} 18$ de la OIT, relativo a las enfermedades profesionales, abordaba este tema de manera incidental, estipulando que "la tasa de esta indemnización (de las enfermedades profesionales) no sería inferior a la que estableciese la legislación nacional por el daño resultante de los accidentes del trabajo".

Un análisis comparado del derecho revela una gran variedad de situaciones. La legislaciones canadienses [ $\left.{ }^{6}\right]$ o la legislación sueca adoptaron un enfoque unitario del concepto de lesión profesional que abarca a la vez los accidentes y las enfermedades. La mayoría de los sistemas jurídicos establece una distinción entre el concepto de accidente laboral y el concepto de enfermedad profesional, aun cuando su indemnización se otorgue dentro de un mismo marco institucional. Estos sistemas pueden consistir en una rama única de la seguridad (en Francia e Italia), un sistema único de seguros sociales (en Alemania y Suiza) o incluso en seguros privados regulados por la seguridad social (en España y Finlandia). En la mayoría de los Estados de EE.UU, al igual que en Reino Unido, los accidentes laborales no representan un concepto diferente al de las enfermedades profesionales. Su indemnización se cubre principalmente por medio de un seguro obligatorio de responsabilidad civil en el que se aplican, no obstante, sistemas específicos para determinadas enfermedades [ $\left.{ }^{7}\right]$ o para ciertas categorías de trabajadores. En 1967, los Países Bajos suprimieron todas las indemnizaciones específicas de la seguridad social por riesgos de trabajo, de manera que los accidentes laborales y las enfermedades profesionales correrían a cargo del régimen de invalidez y enfermedad. La posibilidad de una indemnización complementaria dependería de la responsabilidad civil del empleador. Esto condujo a la creación de un Instituto para las víctimas del amianto, que interviene principalmente cuando el empleador ha desaparecido o no es solvente y cuando los plazos de prescripción imposibilitan la indemnización basada en la responsabilidad civil del empleador. En el supuesto caso de una exposición profesional, se hablaría entonces de una indemnización con carácter residual. El régimen belga deriva de consideraciones estrechamente económicas. Esto significa que la indemnización por accidentes laborales, considerada como una actividad rentable, es competencia de las entidades aseguradoras privadas, mientras que la indemnización por enfermedades profesionales,

Laboreal, Volume $10 \mathrm{~N}^{\circ} 2$ | 2014 
de mayor riesgo, está a cargo de la seguridad social. En Dinamarca y Portugal se adoptó una solución similar.

La exclusión de las enfermedades del campo de aplicación de la ley de 1903 fue el producto de diferentes factores. La visibilidad de los accidentes era inmediata. La definición jurídica que los define como suceso repentino que ocasiona una lesión no planteaba mayores problemas. La jurisprudencia muestra sin embargo que los diferentes elementos de esta definición pueden dar lugar a grandes controversias. La noción de enfermedad profesional implica necesariamente un análisis más complejo. Ninguna enfermedad es intrínsecamente profesional. Aun cuando exista bajan probabilidades de contraer ciertas enfermedades (silicosis, mesotelioma, necrosis de la mandíbula) sin exposición en el trabajo, dichas probabilidades nunca se excluyen. Esta misma exposición puede darse tanto en el caso de trabajadores asalariados y trabajadores autónomos, y en el contexto del trabajo doméstico no remunerado. Las enfermedades se consideran como profesionales únicamente con respecto a la primera categoría. Aparte de estas consideraciones de orden jurídico inherentes a la materia, hay otros factores importantes.

Durante la segunda mitad del siglo XIX tomaron forma tres reivindicaciones del movimiento obrero: la prohibición de los procesos que implicasen una exposición a agentes tóxicos $\left[{ }^{8}\right]$, la posibilidad de recibir una indemnización basándose en la responsabilidad civil del empleador y la instauración de un seguro común que cubriese los accidentes laborales y las enfermedades profesionales. La primera reivindicación se topaba de frente con la facultad otorgada al empleador de organizar la producción. Dicha reivindicación desafiaba uno de los conceptos fundamentales del derecho laboral recién surgido: la noción de subordinación. La segunda reivindicación planteaba menos problemas de principios y era compatible con la visión civilista de las relaciones laborales. Si bien es cierto que el artículo 1385 del Código Civil estipulaba una responsabilidad en el caso de los animales, inclusive en el supuesto de que éstos se hubiesen escapado, también es cierto que no había impedimento alguno de tipo conceptual para introducir en las leyes una responsabilidad derivada de las máquinas y los procesos de producción. La oposición era más bien de tipo político, ya que entablar acciones basándose en la responsabilidad civil del empleador era considerado como una amenaza para la paz social. La perspectiva de una reglamentación común para los accidentes laborales y las enfermedades profesionales implicaba como mínimo definir criterios que permitiesen establecer las diferencias entre estas enfermedades profesionales y otras patologías. La propuesta de Louis Niel, dirigente de la CGT en Francia, presentada en el congreso internacional sobre los accidentes laborales, celebrado en Lieja del 29 de mayo al 4 de junio de 1905, formulaba una definición sintética: "Se considera accidente de trabajo cualquier perturbación del organismo originada por el trabajo o relacionada con éste que provoque una pérdida parcial o total, temporal o permanente, de la calidad productiva del obrero, debido a un debilitamiento de las facultades físicas o fisiológicas de éste" (Devinck, 2010, p. 84, traducción libre). Siguiendo este planteamiento, parecía inevitable establecer un vínculo entre la indemnización y la prevención y desarrollar una reglamentación que limitara la facultad del empleador de organizar el trabajo y decidir sobre los procesos de producción. 


\subsection{La ley sobre las enfermedades profesionales del 24 de julio de 1927 y su evolución} permitía la indemnización por un número reducido de enfermedades profesionales. Esta ley se basaba en el convenio $\mathrm{n}^{\circ} 18$ de la Organización Internacional del Trabajo, adoptado el 10 de junio de 1925. Entre las enfermedades consideradas como enfermedades profesionales sólo se incluían tres grupos. Dos de ellos comprendían enfermedades causadas por sustancias tóxicas (el plomo y el mercurio, así como sus aleaciones y compuestos) y el tercero, las enfermedades causadas por un agente biológico (el carbunco, que se contrae por contacto con animales infectados o con productos animales contaminados). El reconocimiento de estas enfermedades profesionales se limitaba a algunas actividades específicas, las cuales eran ejercidas esencialmente por hombres. Desafortunadamente, no se dispone de datos estadísticos desglosados por sexo que permitan establecer el porcentaje de mujeres beneficiadas en aquella época con el reconocimiento de alguna enfermedad profesional. El mecanismo de indemnización era diferente al que se había instaurado para tratar los accidentes laborales. Los empleadores cuyos trabajadores estuviesen expuestos a alguno de los riesgos identificados por la legislación estaban en la obligación de asegurarse en un organismo único: el Fondo de prevención en favor de las víctimas de enfermedades profesionales.

Los mecanismos establecidos por la ley dificultaban notablemente el reconocimiento de una enfermedad profesional. Aparte del hecho de que las enfermedades profesionales reconocidas como tal eran muy pocas, también se requería que los trabajadores estuviesen empleados en empresas donde se hubiese reconocido dicho riesgo específico y que las mismas cotizasen al sistema de seguridad social. Era el propio trabajador quien tenía que declarar la enfermedad, en plazos muy cortos. La mayoría de los médicos ignoraban la existencia de un sistema de indemnización. Incluso los sindicatos tenían poca formación sobre su funcionamiento.

Durante cuatro décadas, el debate más importante en este terreno estuvo relacionado con la silicosis. Ésta no había sido reconocida como enfermedad profesional ni por el Convenio $n^{\circ} 18$ de la OIT ni por la ley belga de 24 de julio de 1927. En un país donde la actividad minera era fundamental, la silicosis no era desconocida. Ésta constituía un problema de salud pública importante, obligaba a una gran cantidad de mineros a dejar de trabajar mucho antes de la edad de jubilación y generaba una mortalidad masiva. Los artículos médicos que se publicaban sobre los trastornos respiratorios de los mineros eran abundantes. Según Geerkens (2014), el primer estudio médico sobre este tema se publicó en 1827. En 1860 se hizo un estudio mucho más profundo. En la época en la que fue aprobada la primera ley sobre las enfermedades profesionales, la mecanización de las minas estaba aumentando considerablemente el riesgo de contraer silicosis.

El reconocimiento de la silicosis como enfermedad profesional ya había comenzado en otros países. En Sudáfrica, las enfermedades pulmonares de los trabajadores de las minas de oro empezaron a ser consideradas como enfermedades profesionales a partir de 1912, aun cuando las diferencias de trato entre los mineros blancos y negros eran enormes. Considerando que la legislación compensaba la pérdida de ganancias en el mercado laboral, las indemnizaciones de los mineros negros equivalían aproximadamente al $10 \%$ de las cantidades asignadas a los mineros blancos con un

Laboreal, Volume 10 N² | 2014 
mismo nivel de discapacidad. Los mineros blancos recibían una renta, mientras que los mineros negros tenían que conformarse con una suma fija que se hacía en un solo pago. Por otra parte, el derecho que tenían los mineros negros a recibir indemnizaciones era limitado. Los médicos de las compañías de explotación minera raras veces diagnosticaban la silicosis en los mineros negros. En Gran Bretaña, la silicosis se incluyó entre las enfermedades profesionales reconocidas en 1918. A partir de 1925, las organizaciones sindicales internacionales comenzaron a solicitar que el Convenio de la OIT sobre las enfermedades profesionales abarcara también la silicosis. Se necesitaron casi diez años para que fuese aprobado, en junio de 1934, el Convenio ํo 42 de la OIT, por el que se revisaba la lista de enfermedades profesionales. La OIT añadió 7 grupos de enfermedades a los tres grupos que ya habían sido reconocidos en 1925. Sin embargo, el texto del Convenio $\mathrm{n}^{\mathrm{o}} 42$ presentaba, en lo que concierne a la silicosis, algunas ambigüedades. El texto adoptaba una condición que no se planteaba con ninguna otra enfermedad, ya que la consideraba enfermedad profesional "siempre que la silicosis sea una causa determinante de incapacidad o muerte". Así mismo, el convenio otorgaba a los Estados un margen de interpretación inusual, puesto que éstos podían declarar que la silicosis era una enfermedad profesional sólo en el caso de "las industrias u operaciones que la legislación nacional considere están expuestas a los riesgos de la silicosis" (artículo 2 del Convenio no 42 de la O.I.T., 1934).

La demora de Bélgica es el resultado de la influencia hegemónica que ejercía la patronal minera no sólo en los debates políticos, sino también en los trabajos científicos relativos a la silicosis. La mayoría de los médicos que intervenían en las minas, así como los expertos académicos en el área de las enfermedades respiratorias, colaboraban con las investigaciones que sostenían que las neumoconiosis "no son una enfermedad en el verdadero sentido de la palabra". Incluso hubo un geólogo que afirmaba que los trabajadores de las minas belgas no estaban expuestos a la sílice. La opinión médica oscilaba entre dos extremos. Por una parte, ésta insistía en que los estudios que se habían hecho hasta el momento eran insuficientes y que era necesario iniciar otras investigaciones antes de sacar cualquier conclusión y, por otro lado, consideraba que las enfermedades respiratorias de los mineros se debían principalmente a la tuberculosis, que debía considerarse como un problema de salud pública, ajeno a las condiciones de trabajo.

\subsection{El acuerdo de 1937: una construcción frágil que duró un cuarto de siglo}

40 El movimiento sindical no cuestionó de manera radical la opinión científica inculcada por el mundo empresarial y se fijó el objetivo de lograr que los obreros que sufrían enfermedades respiratorias fuesen indemnizados. Tras la huelga general de junio de 1936, el ministro socialista del trabajo Delattre (antiguo dirigente del sindicato de mineros) propuso que todas las enfermedades provocadas por polvos industriales se considerasen enfermedades profesionales. Con este argumento se neutralizaba la polémica sobre el papel específico de la sílice. Frente a esta amenaza, la patronal minera declaró que en las minas belgas no había enfermedades respiratorias causadas por la inhalación de polvo. Dado que en un contexto marcado por la huelga general de 1936 era inevitable ceder ante el movimiento sindical, la patronal propuso el siguiente acuerdo: dejar de aplicar de manera definitiva la ley sobre las enfermedades profesionales en las minas de carbón belgas a cambio de mejorar el régimen de 
pensiones de los obreros de la mina, que databa de 1914 [ $\left.^{[}\right]$. Tras arduas negociaciones, el acuerdo propuesto por la patronal fue aceptado. La ley de 25 de junio de 1937 modificaba el régimen de pensiones de los mineros inválidos. En virtud de ello, cualquier obrero que hubiese perdido sus capacidades para "trabajar normalmente" podía solicitar una pensión por invalidez. Para obtenerla, se requería haber trabajado como minero de fondo durante un número determinado de años, que variaba en función de la edad, pero que nunca era inferior a los 10 años. El importe de la pensión era en aquel entonces más elevado que la indemnización que se otorgaba con arreglo al régimen de enfermedades profesionales. El efecto perverso de este sistema radicaba en que los mineros seguían trabajando en el fondo de la mina hasta cumplir el número de años requeridos, con lo cual la silicosis por lo general se agravaba antes de que pudieran acceder a la pensión. El régimen dependía de tres fuentes de financiación: 1/6 estaba constituido por cotizaciones patronales, $1 / 6$ por cotizaciones de los trabajadores y $2 / 3$ por presupuesto estatal.

41 Al finalizar la Segunda Guerra Mundial, el derecho laboral fue modificado a través de numerosas reformas que se llevaron a cabo en un contexto político en el que tambaleaba la legitimidad del poder de las clases dominantes. Sin embargo, la salud laboral no fue considerada en estas transformaciones.

Una de las reformas más importantes fue la creación de la seguridad social. En Francia se aprovechó la oportunidad para decretar por fin la indemnización de la silicosis y para crear una rama única de riesgos laborales dentro del régimen general de la seguridad social. En Bélgica se impuso un conservadurismo cauteloso. Desde el punto de vista de la coherencia jurídica, resultaba extraño que se mantuviese un enclave totalmente privado (accidentes laborales) y otro enclave basado en la capitalización (hasta 1950, en lo que respecta a las enfermedades profesionales) dentro de un sistema público general basado en el reparto.

En relación con el tema específico de la silicosis, la razón más importante que permite explicar la diferencia entre Francia y Bélgica radica probablemente en que Bélgica recurría en forma intensiva al empleo de trabajadores inmigrantes.

En Francia, fue preciso que hubiera una guerra y que la industria del carbón se viese enfrentada a dificultades en la contratación de obreros para que el régimen de Vichy considerara la posibilidad de reconocer a la silicosis como una enfermedad profesional. No obstante la oposición del patronato, se logró la elaboración de varios textos que fueron contando con un apoyo creciente por parte de los médicos. Después de junio de 1944, los textos elaborados por el régimen de Vichy se utilizaron como base para el nuevo Gobierno provisional surgido de la resistencia. Jean-Paul Devinck y Paul-André Rosental comentan en estos términos la orden ministerial emitida el 2 de agosto de 1945 por la que la silicosis pasó a formar parte de la lista de enfermedades profesionales: "Esta orden ministerial, presentada como el reconocimiento justo que se le hacía a una reivindicación de los mineros, es en realidad consecuencia de una relación de fuerzas, ampliamente establecida bajo el régimen de Vichy, entre los diferentes ministerios involucrados y el Comité Central de Empresas Mineras de Francia". La orden ministerial estipulaba, no obstante, varias condiciones restrictivas que se justificaban con el argumento de que "la silicosis evoluciona y se manifiesta en condiciones tan particulares que resulta imposible aplicarle el derecho común relativo a las enfermedades profesionales" (Devinck \& Rosental, 2009, pp. 123-124, traducción libre). 

belgas, bien representados dentro de los sindicatos y relativamente protegidos por el régimen de pensiones por invalidez, y los mineros inmigrantes, a quienes los sindicatos mayoritarios ofrecían poco amparo [13]. Esta brecha también era producto de una cierta división del trabajo, siendo que a los mineros inmigrantes solía asignárseles las tareas más pesadas y más expuestas.

\subsection{La ley de 24 de diciembre de 1963: reforma general y reconocimiento de la silicosis}

El régimen de pensiones por incapacidad laboral establecido en 1937 era originalmente más favorable desde el punto de vista económico de lo que habría sido la indemnización de la silicosis como enfermedad profesional. Sin embargo, esta ventaja no se mantuvo. Según los cálculos hechos por Eric Geerkens (2014), se presume que el régimen de enfermedades profesionales hubiera permitido, a partir de 1951, obtener una 
indemnización mayor en comparación con la jubilación por invalidez concedida a los mineros; situación que contribuyó a que se replantease dentro de los sindicatos la cuestión relativa al reconocimiento de la silicosis.

Así mismo, se dio marcha atrás a la monetización de los riesgos laborales como consecuencia de la catástrofe de Marcinelle, ocurrida el 8 de agosto de 1956, en la que perdieron la vida 262 mineros. En un contexto caracterizado por movilizaciones sociales, la cuestión relativa a la silicosis afloró nuevamente.

52 Se entablaron entonces negociaciones difíciles que permanecen bloqueadas durante más de 5 años. Finalmente el Parlamento terminó adoptando el 24 de diciembre de 1963 una ley por la que se reformaba todo el sistema de reconocimiento e indemnización de las enfermedades profesionales y se incluía la silicosis en la lista de enfermedades consideradas como enfermedades profesionales.

53 La ley de 24 de diciembre de 1963 marca un hito en muchos aspectos. El marco jurídico e institucional para el reconocimiento de las enfermedades profesionales se transformó profundamente. A partir de entonces, dichas enfermedades se consideraron de manera inequívoca como una rama de pleno derecho de la seguridad social, solución ésta que nunca había recibido una aprobación unánime. Ugeux recuerda que "en 1953, el Consejo Nacional del Trabajo se había pronunciado en contra de la inclusión de las enfermedades profesionales en el marco técnico de la seguridad social porque consideraba que dicha inclusión no estimularía a las empresas a ocuparse de la prevención a partir del momento en que los riesgos inherentes a algunas de dichas empresas fuesen asumidos totalmente por las industrias en su conjunto" (Ugeux, 1995, p. 30, traducción libre).

54 La ley crea el Fondo de Enfermedades Profesionales (FMP, por sus siglas en francés), administrado paritariamente por un comité de gestión. La nueva ley establece una fórmula de financiación mixta que combina una cotización de solidaridad percibida de acuerdo a una base uniforme y una cotización de prevención que pagarían las empresas pertenecientes a los sectores industriales considerados de mayor riesgo. Finalmente no se puso en práctica la segunda fórmula. El $50 \%$ de la indemnización correspondiente a las neumoconiosis se sufragó con cargo al presupuesto del Estado, porcentaje que fue elevado al 65\% en 1970.

Esta ley abandonó el sistema instaurado en 1927 que establecía una relación entre determinadas actividades laborales y riesgos específicos. Según la ley de 1963, una enfermedad profesional se caracteriza por una exposición determinada, independientemente del sector, profesión o actividad donde se haya producido dicha exposición. Pero sigue habiendo excepciones, algunas de las cuales se explican fácilmente al analizar las condiciones de trabajo. Algunas enfermedades infecciosas sólo figuran en la lista de enfermedades profesionales a condición de que las mismas figuren en el contexto de la atención sanitaria. Algunas condiciones tenían un carácter más arbitrario, como ocurrió durante mucho tiempo con los casos de tendinitis, cuyo reconocimiento, de acuerdo a la lista de enfermedades profesionales, se limitaba a las profesiones de las artes y el espectáculo. El Decreto de 12 de octubre de 2012 pone fin a esta situación, que había suscitado un gran número de críticas.

Son varios los factores que contribuyeron al reconocimiento de la silicosis, si bien ninguno de ellos se relaciona directamente con los conocimientos médicos. Por el contrario, la institución de referencia para la salud en las minas era el Instituto Belga 
de Higiene de Minas de Hasselt, creado en enero de 1944 por la patronal minera. Uno de los objetivos formulados de manera explícita en los documentos constituyentes de esta institución científica era "evitar la adopción de medidas de origen legislativo o reglamentario -por ejemplo, en el ámbito del régimen de enfermedades profesionalesque engendren cargas muy elevadas para la industria del carbón, sin que por ello se responda a los objetivos propuestos" (Geerkens, 2009, p. 139, traducción libre). La tardanza en el reconocimiento de la silicosis tiene que ver con peculiaridades en la historia social de Bélgica.

Hasta 1944 puede verse claramente el paralelismo que existe entre Francia y Bélgica. Ambos países se niegan a reconocer la silicosis e invocan argumentos médicos similares. Sin embargo, la gestión social de dicha situación es diferente. En Bélgica, la combatividad sindical fue apaciguada con la instauración, en 1937, de un sistema de pensiones para los mineros inválidos. No obstante, este régimen estaba sujeto a condiciones limitativas, entre ellas, el hecho de que la pensión de invalidez sólo se otorgase en el caso de que el minero estuviese aún activo en el momento del reconocimiento de dicha invalidez. En la práctica, esto obligaba a los mineros que comenzaban a padecer los primeros síntomas de la silicosis a seguir exponiéndose al riesgo de modo tal que su situación se degradaba a tal punto que terminara reconociéndose su incapacidad. Este acuerdo ofrecía por lo tanto un beneficio social que iba en detrimento de la salud.

Los factores que finalmente hicieron que se reconociera la silicosis son los siguientes:

1. Una movilización social cada vez mayor de los mineros italianos inmigrantes reivindicando el reconocimiento de la silicosis como enfermedad profesional. Estos hechos han podido reconstruirse gracias principalmente a una labor de memoria histórica. Hasta donde sepamos, ningún historiador los abordó de manera sistemática. La principal organización sindical italiana, la CGIL, desempeñó en este contexto un papel importante mediante la participación de un organismo específico (el INCA) $\left.{ }^{[14}\right]$ destinado a defender los derechos sociales de los trabajadores italianos tanto dentro de su país como fuera de él. Esta forma de representación colectiva ayudó a compensar las reticencias y divisiones de los sindicatos belgas.

2. Esta movilización desencadenó también una crítica a los planteamientos médicos predominantes. En Bélgica, las posiciones expresadas tanto en las publicaciones médicas como en la enseñanza universitaria variaban desde la negación total hasta la duda prudente. Sólo unos cuantos médicos (entre ellos, el radiólogo Jacques Lemaitre), grandes defensores de los mineros, consideraban que no cabía duda alguna de que la silicosis era efectivamente una enfermedad profesional. Sus argumentos se apoyaban en sus propias observaciones clínicas. A fin de contrarrestar la influencia de los médicos que se oponían al reconocimiento de la silicosis, se organizó en 1960 un coloquio en Lieja, que dio lugar posteriormente a una campaña muy activa.

3. La situación en Bélgica generaba inquietud entre sus socios europeos. Eran decenas de miles los mineros italianos que habían trabajado en las minas belgas y habían contraído la silicosis. Estos se veían afectados por una discriminación indirecta a la hora de ponerse en práctica las normas relativas a la pensión de los mineros que sufrían de invalidez; normas éstas que constituían en aquella época el único régimen por el que se podía recibir indemnización por silicosis. Estas normas establecían requisitos en materia de antigüedad que eran más fáciles de cumplir para los mineros belgas que para los mineros inmigrantes. Italia, presionada por los partidos de izquierda y el movimiento sindical, adoptó el 27 de julio de 1962 la ley n1115, gracias a la cual los mineros que habían contraído la silicosis en Bélgica podían recibir indemnizaciones de la seguridad social italiana, siempre y cuando hubiesen retornado y 
viviesen nuevamente en Italia. Se trataba de una ley de excepción basada en el principio de equidad. Sus disposiciones eran contrarias a los principios del derecho comunitario de la seguridad social. ¿Por qué algunos trabajadores debían ser indemnizados por su país de origen cuando su enfermedad había sido ocasionada en otro país donde dichos trabajadores cotizaban para la seguridad social? Esta ley había sido concebida como una medida transitoria hasta que Bélgica declarase la silicosis como enfermedad profesional. También era una manera de presionar al legislador belga a fin de que éste cumpliese con su deber. En noviembre de 1961, se trasladó a Bélgica un grupo de senadores italianos. La realización de esta visita había sido coordinada conjuntamente con varios activistas sindicales italianos que intervenían en las minas belgas y que habían recolectado 15.000 firmas para una petición. Fue necesario mantener vigente esta ley transitoria debido a la aplicación restrictiva de la legislación belga después de 1963.

4. Con la adopción, el 23 de julio de 1962, de su primera recomendación relativa al reconocimiento de las enfermedades profesionales, la Comisión Europea efectuó una llamada al orden. El Anexo 1 de la recomendación establecía una lista uniforme a nivel europeo de las enfermedades o agentes que las podían provocar. Esta lista correspondía a las enfermedades sobre las que los Estados miembros debían establecer disposiciones para fines de indemnización. La silicosis figuraba obviamente en esta lista. Había una segunda lista (anexo II) referente a las enfermedades que debían ser notificadas a fin de que las mismas, de ser el caso, fuesen incluidas en la primera lista $\left[{ }^{15}\right]$. Cabe añadir que la libre circulación de los trabajadores debía, en principio, poner fin al régimen de restricción específica que limitaba la libertad de los trabajadores italianos, impidiéndoles escoger el empleo que éstos quisieran. Sin embargo, después del grave accidente de Marcinelle en 1956, la contratación de mineros se orientó principalmente hacia los trabajadores griegos, turcos y marroquíes.

5. Los argumentos sobre la paz social y su costo para la industria, que habían contribuido a bloquear todo tipo de reglamentación, jugaban ahora a favor del reconocimiento de la silicosis. El proceso de cierre de las minas de carbón ya estaba en marcha. Según Fedechar, el número de mineros había pasado de poco más de 177.000 trabajadores en 1948 a 88.500 en 1961. El reconocimiento de la silicosis era, al parecer, una manera de contribuir a la paz social, ya que con la indemnización de su enfermedad profesional, algunos mineros despedidos veían completadas sus prestaciones por desempleo y las pensiones de jubilación. El costo de las indemnizaciones por silicosis debía correr en parte por cuenta del Estado, cuya contribución, fuera de las normas del derecho común relativo a las enfermedades profesionales, representaba el 50\%. A este respecto, se puede establecer un paralelismo con la creación en 2006 del Fondo Asbesto. En este caso, se rechazó la hipótesis de una financiación directa a cargo de las empresas que habían trabajado utilizando el asbesto. El Estado asumió el 50\% del presupuesto inicial del Fondo y el resto provino de un aporte mutualista de todos los empleadores.

\subsection{Reformas legislativas ulteriores y evolución en materia reglamentaria}

No haré referencia aquí a las numerosas modificaciones por las que pasó el régimen sobre enfermedades profesionales durante medio siglo. El principal reproche que se puede hacer al poder legislativo es el de haber multiplicado las enmiendas y añadidos de manera instrumental. Algunos son perfectamente legítimos y no afectan la lógica global del sistema (introducción del sistema abierto), pero otros obedecen a razones puramente económicas. En ocasiones, la ley sólo sirve para legitimar algunas prácticas administrativas cuya legalidad es cuestionable (como recurrir a la noción de causalidad para definir el riesgo profesional). Esta navegación de cabotaje sacrificaba la coherencia 
global del sistema y lo volvía ilegible para sus beneficiarios potenciales. Mi propia experiencia, tanto con los delegados sindicales como con los asesores en materia de prevención, me indica que éstos comprendían mucho mejor la legislación sobre accidentes laborales que las normas relativas a las enfermedades profesionales.

Las reformas más importantes tuvieron lugar con la introducción en 1990del sistema abierto, y con la redefinición en 2006de lo que se debía entender por riesgo profesional, tras la adopción del nuevo concepto de "enfermedad relacionada con el trabajo".

\subsubsection{Un sistema (poco) abierto}

61 La ley de 29 de diciembre de 1990 introdujo el artículo 30bis en la ley del 24 de diciembre de 1963. Veinticuatro años después de la recomendación comunitaria del 20 de julio de 1966 que preconizaba esta medida, el legislador belga terminó aprobando el "sistema abierto". En el nuevo contexto cualquier patología puede ser reconocida como una enfermedad profesional con la condición de que la víctima (o sus derechohabientes) demostrase que la causa determinante y directa de dicha enfermedad radica en el ejercicio de la profesión. El sistema impone tres elementos probatorios: la patología, las condiciones de trabajo que hayan podido causarla y la causalidad "determinante y directa". El tercer elemento es el que plantea mayores dificultades. El sistema abierto tiene que cumplir dos funciones; una colectiva: ayudar a colmar progresivamente las lagunas del sistema de lista, y otra individual: garantizar la indemnización de las personas que logren ofrecer la carga de la prueba.

La jurisprudencia y la doctrina han demostrado que la carga de la prueba es una condición difícil de cumplir, lo cual explica la escasa eficacia del dispositivo establecido. La gran mayoría de las enfermedades indemnizadas se relacionan con un código de la lista al que se atribuye de manera unánime un carácter arbitrario: se trata de las tendinopatías, cuya indemnización, con arreglo a la lista, sólo puede concederse a los artistas del espectáculo. De acuerdo al sistema abierto, entre 1991 y 2012 las tendinitis representaron aproximadamente 8 de cada 10 indemnizaciones otorgadas por el Fondo de Enfermedades Profesionales. Esto nos sitúa aún muy lejos del objetivo establecido en los trabajos parlamentarios previos a la adopción de la ley de 29 de diciembre de 1990, según los cuales era necesario flexibilizar el sistema de reconocimiento para adaptarlo a la gran diversidad de enfermedades causadas por el trabajo. Las dificultades surgidas tuvieron un efecto disuasivo indudable, y las solicitudes de indemnización se mantuvieron por lo tanto en un nivel muy bajo.

La eficacia del sistema abierto ha sido muy limitada. Desde su creación en 1990, la media actual de los trabajadores indemnizados por incapacidad permanente se ha situado por debajo de los 40 casos por año (lo que representa menos del 5\% del total de las enfermedades profesionales indemnizadas). En 22 años, no se ha reconocido ningún caso de cáncer en el marco del sistema abierto.

\subsubsection{La reforma de 2006: la opción de la incoherencia}

En 2006, el poder legislativo introdujo una nueva noción: la de la enfermedad relacionada con el trabajo. Se entiende por tal una enfermedad que, sin llegar a ser una enfermedad profesional, podría de todas formas llegar a serlo de no disponerse de una prevención adecuada. La formulación jurídica del texto es confusa y los trabajos preparatorios no aportan esclarecimiento alguno. En realidad, se trata de una reforma 
"ad hoc", puramente instrumental, destinada a impedir que las lumbalgias fuesen reconocidas como enfermedades profesionales tanto dentro del sistema de lista como dentro del sistema abierto [16]. Ante esta perspectiva, que nos retrotrae a la historia de la silicosis, se insistió en conseguir que el Fondo de Enfermedades Profesionales financiara las medidas de prevención. Era inútil introducir un nuevo concepto jurídico para llegar al mismo resultado. Desde su creación, dicho concepto se aplicó a una sola patología, aun cuando la definición hubiera podido cubrir cientos de enfermedades diferentes. El Parlamento se comportó con una docilidad ejemplar, como se evidencia en los documentos parlamentarios que parafrasean el informe del Ministerio. En derecho comparado, ninguna otra legislación emplea este concepto en el contexto de la indemnización por enfermedades profesionales.

Las intervenciones del Fondo de Enfermedades Profesionales se mantienen en un nivel moderado. En 2012, el programa de prevención de enfermedades de la espalda abarcó 832 trabajadores (mujeres en su mayoría). Según los datos relativos a Bélgica provenientes de la encuesta europea de 2010sobre condiciones de trabajo, el 39,2\% de los hombres y el $22,9 \%$ de las mujeres que trabajan están expuestos al transporte de cargas pesadas, mientras que el $15,7 \%$ de las mujeres y el $6,1 \%$ de los hombres que trabajan se ven obligados a levantar o desplazar personas durante el ejercicio de su actividad profesional [17]. Estos datos no permiten calcular el porcentaje de trabajadores que padecen lumbalgias causadas o agravadas por su trabajo. Revelan, sin embargo, que se trata de un problema de magnitud significativa. Las condiciones de intervención del Fondo de Enfermedades Profesionales se establecieron en términos suficientemente restrictivos, de tal manera que, desde el punto de vista presupuestario, la medida se inscribiera diera lugar a intervenciones puntuales y no a una estrategia de prevención.

66 La intervención de la Ministra del Trabajo durante el debate parlamentario sobre la adopción de esta ley es desconcertante: "Se pueden encontrar enfermedades relacionadas con el trabajo en la población en general; me refiero a la población no expuesta en el contexto de una actividad profesional. Las influencias nocivas producto de la exposición profesional sólo acarrean un ligero aumento de la enfermedad. La exposición al riesgo profesional no es, por consiguiente, la causa principal de la enfermedad, sino uno de los factores de agravamiento". Todos los criterios antes enunciados son refutables. El primero es trivial: no hay ninguna enfermedad profesional que no se dé también en la "población en general". La articulación entre los dos criterios siguientes carece de relación lógica. El criterio estadístico ("ligero aumento") no incide de manera directa en la causalidad. Gracias a medidas de prevención eficaces una enfermera puede contaminarse con el virus de la hepatitis en su trabajo (relación de causalidad) sin que dicha situación tenga una influencia significativa en el aumento de la enfermedad en la población involucrada. Una enfermedad profesional poco frecuente que no contribuye a una prevalencia significativamente superior de la morbilidad en un determinado grupo profesional no deja de ser por ello una enfermedad profesional. Una enfermedad cuya prevalencia es alta en la población en general también puede constituir una enfermedad profesional, aun cuando no se observen variaciones estadísticas importantes (algunos tipos de cáncer de la piel). ¡La prevención a veces es eficaz! La ministra concluye diciendo que "En la práctica, el ente que se encargará de sugerir cuáles son las enfermedades 
relacionadas con el trabajo y de determinar cuáles son las poblaciones de riesgo es el comité de gestión del Fondo de Enfermedades Profesionales" [ $\left.{ }^{18}\right]$.

El asunto merecía una menor improvisación. La intensificación del trabajo es la causa de una progresión rápida de los trastornos musculo-esqueléticos (TME). El problema involucra a todos los sectores, y resta visibilidad a aquellos trastornos de la salud que son cada vez menos característicos de una actividad concreta. El debate sobre los trastornos dorsolumbares se inscribe en este contexto. Éste presenta algunas similitudes con las controversias sobre las enfermedades respiratorias en las minas. En ambos casos, el debate gira primeramente en torno a un conjunto muy amplio de patologías. Progresivamente se establece una nomenclatura destinada a diferenciar estas enfermedades. Sin embargo, la operación de clasificación nunca es neutra. Ésta refleja la realidad hasta tal punto de que la misma condiciona su aprehensión. Una clasificación puede ser eficaz para ciertos fines (por ejemplo, para orientar mejor una intervención terapéutica) y convertirse en una fuente de confusión en un contexto diferente (por ejemplo, cuando se trata de organizar la prevención en el lugar de trabajo). Los lumbagos se refieren más a un síntoma que a una enfermedad. Los trastornos dorsolumbares designan una localización. La noción de silicosis surgió en los debates de manera tardía. Esta denominación hace referencia a una exposición específica (la fracción inhalable de la sílice) y la misma se inscribe en un conjunto mucho más amplio de enfermedades neucomonióticas. El rasgo común de estas enfermedades es que todas son patologías pulmonares causadas por la inhalación de polvo. La distinción entre la asbestosis (polvo de amianto), la antracosis (polvo de carbón), la siderosis (polvo de hierro), la silicosis, etc. se fue haciendo de manera progresiva. Desde el punto de vista médico, diferenciar las patologías en función de su agente causal no tiene nada de ilógico, tanto más cuanto que dichas patologías pueden presentar diferencias notables en lo que se refiere a su evolución. Pero proceder de la misma manera en lo que respecta a los trastornos dorsolumbares es una tarea imposible, ya que su etiología es multicausal. En ella intervienen múltiples factores. Por consiguiente, no tendría ningún sentido intentar establecer una nomenclatura médica que estableciera la diferencia entre las enfermedades causadas por el transporte de cargas y aquellas provocadas por las vibraciones mecánicas o posturas forzadas. Comparando las diferentes enfermedades se puede comprobar que ciertos factores juegan un papel más importante, sin excluir por ello la relación de causalidad que pueda existir con respecto al resto de los factores. En todo caso, es imposible identificar una causalidad preponderante.

Un elemento importante que tienen en común los trastornos dorsolumbares y las enfermedades neucomonióticas es la inmensa variabilidad de nexos que existe entre las imágenes médicas y la gravedad de la patología a nivel individual. En ambos casos, las radiografías críticas pueden corresponder a un estado de salud que se considera bueno. Lo contrario también es posible; es decir, imágenes menos inquietantes que tengan que ver con dificultades respiratorias más graves (en el caso de las neumoconiosis) y con dolores o una minusvalía en el caso de la patologías dorsolumbares. En el campo de la salud dicha constatación no tiene nada de extraordinario. Lo que puede medirse o captarse a través de una imagen no proporciona más que un elemento particular del diagnóstico. La inteligencia clínica consiste en la capacidad de combinar una variedad de elementos de información en los que la percepción del paciente tiene un papel determinante. No existen métodos que permitan medir con precisión el dolor, las dificultades respiratorias (las indicaciones que da la espirometría son limitadas), la 
percepción que tiene el paciente de su enfermedad y la estrategia de adaptación física y mental que pone en práctica en función de ella. Se trata de rasgos comunes a todos los trastornos musculo-esqueléticos. Ya se trate del síndrome del túnel carpiano o de la tendinitis, los elementos del diagnóstico pasan necesariamente por una serie de métodos de investigación, y la calidad de la relación entre el personal médico y el paciente es un elemento importante. Por otra parte, si el propósito es establecer una relación con las condiciones de trabajo, es indispensable conocerlas. En lo que respecta al síndrome del túnel carpiano, por ejemplo, existe un serie de pruebas (prueba de Tinel, prueba de Phalen) y exámenes electro-diagnósticos. Ninguno de estos métodos ofrece resultados de una certeza absoluta, y su superposición puede generar informaciones contradictorias. Cabe admitir la posibilidad de que, para fines de atención terapéutica, los criterios de clasificación jurídica (en la lista) difieran de otros criterios, de tipo médico.

Si queremos aprender alguna lección de la historia de la silicosis, es preciso hacer hincapié en la diferencia que existe entre ciertos datos objetivables (en el caso de la silicosis principalmente la radiografía, con un margen de error derivado de la interpretación de la imagen) y la enfermedad como daño global a la salud. Ninguno de los médicos que se manifestaron en contra del reconocimiento de la silicosis como enfermedad profesional actuó necesariamente de esa manera porque se identificaba con los intereses patronales. La construcción social de los conocimientos médicos no se reduce a compromisos ideológicos o fenómenos de corrupción. Hay obstáculos científicos reales, y el lenguaje de la ciencia es el de la duda, de las conclusiones provisionales y prudentes y la necesidad de investigación adicional.

La función del derecho es diferente. A éste le corresponde zanjar los asuntos planteados. El legislador, a través de los textos de alcance general, y el juez, calificando de manera concreta los hechos que le son expuestos, no pueden evitar responder. A ambos no les está permitido dudar o, dicho en forma más precisa, tienen la obligación de tomar una decisión a partir de una duda ciñéndose a las reglas propias del derecho, que les permitirán zanjar en un sentido $u$ otro (es una de las funciones que cumplen las presunciones). Una patología será calificada como enfermedad profesional o no lo será. Es una operación colectiva en cuanto a la redacción de la lista, pero individual en caso de impugnación judicial ajena al debate científico, aun cuando éste último intervenga en la argumentación desarrollada. En el ámbito médico, la cuestión se plantea en términos diferentes y plurales. El origen profesional, cuando se trata de una terapia individual, representa rara vez un elemento pertinente, salvo en el caso eventual de una exención de prestar servicio o de una reincorporación al trabajo. La cuestión supone un interés mayor en el campo de la prevención, pero, en este caso, la respuesta no excluye un amplio margen de incertidumbres y controversias que atraviesan toda la historia de la salud en el trabajo. El enfoque preventivo no es en sí mismo unidisciplinario pues combina métodos diferentes con procesos de validación que le son propios.

\section{Conclusión}

71 La noción de enfermedad profesional surgió a principios del siglo XX en la confluencia de tres corrientes: el desarrollo de la medicina laboral, cuyo objetivo era evitar la aparición de "patologías profesionales"; la elaboración jurídica de la noción de "riesgo 
profesional", que monetizaría una parte de los daños a la salud causados por el trabajo; y las movilizaciones sociales en defensa de la vida y la salud de los trabajadores y en contra de su explotación. Las autoridades públicas jugaron por su parte un papel importante pues disponían de instrumentos eficaces tanto para reglamentar directamente como para influir en el resto de los actores (represión del movimiento obrero durante todo el siglo XIX, intentos de integración del movimiento obrero y de mediación entre éste y el mundo patronal durante el siglo XX). El reconocimiento de las enfermedades profesionales en Bélgica ha seguido una trayectoria general que se asemeja a la de los demás países industrializados. No obstante, su inmensa tardanza en el reconocimiento de la silicosis exige explicaciones específicas. La misma obedece a diferentes factores. De manera general, el movimiento sindical no ha considerado la construcción del conocimiento médico como un terreno conflictivo atravesado por la lucha de clases. Los sindicatos aceptaron los acuerdos propuestos por la patronal, que al menos en sus comienzos, favorecían a los trabajadores desde el punto de vista de la monetización del riesgo pero tenían efectos negativos en materia de prevención. La tradición paritaria representó por su parte un gran freno e impidió que se desarrollara una línea sindical autónoma sobre las cuestiones de salud laboral. La actividad y la organización autónomas de los trabajadores inmigrantes más explotados tuvieron gran influencia en la creación de las condiciones para que se produjera un cambio, pues fueron más allá de los límites trazados por las organizaciones sindicales mayoritarias.

\section{BIBLIOGRAFÍA}

Chlepner, CChlepenerBB .S. (1972), Cent ans d'histoire sociale en Belgique. Bruxelles: Editions de l'Université Libre de Bruxelles.

Devinck J.C., \& Rosental, P.A. (2009). 'Une maladie sociale avec des aspects médicaux' : la difficile reconnaissance de la silicose comme maladie professionnelle dans la France du premier XXe siècle. Revue d'histoire moderne et contemporaine, $\mathrm{n}^{\circ}$ 56-1, pp. 99-126.

Devinck, J.CL. (2010). La lutte contre les poisons industriels et l'élaboration de la loi sur les maladies professionnelles. Sciences sociales et santé, vol. 28, n²-2010, pp. 65-93.

Geerkens, E. (2009). Quand la silicose n'était pas une maladie professionnelle. Genèse de la réparation des pathologies respiratoires des mineurs (1927-1940). Revue d'histoire moderne et contemporaine 1/2009, n 56-1, p. 127-141.

Geerkens, E. (2014). La pneumoconiose des ouvriers mineurs en Belgique (1937-1970). In J. Rainhorn, Santé et travail à la mine. XIXe-XXIe siècle. Lille: Presse Universitaire du Septentrion.

IHOES (1998), « Siamo tutti neri! Des hommes contre du charbon. Etudes et témoignages sur l'immigration italienne en Wallonie, Seraing: Institut d'histoire ouvrière, économique et sociale.

Lécuyer B.P. (1983). Les maladies professionnelles dans les « Annales d'hygiène publique et de médecine légale » ou une première approche de l'usure au travail. Le Mouvement Social, $\mathrm{n}^{\circ}$ 124, pp. 45-69. 
Lippel, K. (2003). Compensation for musculoskeletal disorders in Quebec : systemic discrimination against women workers? International Journal of Health Services, vol. 33, $\mathrm{n}^{\circ} 22$, pp. 253-281.

Lippel, K., \& Cox, R. (2012). Invisibilité des lésions professionnelles et inégalités de genre : le rôle des règles et pratiques juridiques. In A. Thébaud-Mony, V. Daubas- Letourneux, N. Frigul, P. Jobin, Santé au travail. Approches critiques. Paris: La Découverte, pp. 1593-179.

Lippel, K., \& Lefebvre, M.C. (2014). La reconnaissance des troubles musculo-squelettiques en tant que lésions professionnelles en droit québécois. Cowansville: Ed. Yvon Blais.

Morelli, A. (1988). L'appel à la main d'œuvre italienne pour les charbonnages et sa prise en charge à son arrivée en Belgique dans l'immédiat après-guerre. Revue Belge d'Histoire Contemporaine, XIX, 1-2, pp. 83-130.

Ramazzini, B. (2012). Tratado sobre las enfermedades de los trabajadores, Madrid: INSHT.

Supiot, A. (1994). Critique du droit du travail. Paris : PUF.

Ugeux, J. (1995). L'assurance contre les maladies professionnelles. Cinquante ans de sécurité sociale... et après ?, vol. 5 : Quand le travail nuit à la santé, pp. 11-42. Bruxelles : Bruylant.

\section{NOTAS}

1. Los territorios que conforman el Estado belga a partir de 1830 formaron parte de Francia entre 1795 y 1815. Un gran parte de las instituciones jurídicas belgas contemporáneas surgieron durante este periodo francés.

2. El texto completo de los tres volúmenes del informe puede consultarse en el sitio web "Gallica" de la Biblioteca Nacional de Francia.

3. En agosto de 1836 se instauró en Bruselas un consejo central de salubridad pública. Seguidamente se crearon consejos provinciales en Amberes, Brujas y Lieja. Estos consejos, compuestos principalmente por médicos, desempeñaban una función consultiva. Éstos seguían el ejemplo de Francia, que, a partir de 1802, comenzó a crear consejos de salubridad pública con el principal objetivo de estudiar los efectos nocivos de las actividades industriales.

4. Tal es el caso de las encuestas realizadas en Francia por Parent-Duchâtelet y d'Arcet y publicadas en 1829, la encuesta de Villermé, realizada en Francia entre 1835 y 1837, y el libro de Engels "La situación de la clase obrera en Inglaterra" (1845), basado en los contactos personales del autor con militantes obreros y al mismo tiempo en las investigaciones parlamentarias.

5. Este aspecto sigue siendo de vital importancia para interpretar correctamente las investigaciones epidemiológicas y las encuestas sobre las condiciones de trabajo. Trabajar en condiciones nocivas produce un efecto de selección, que la literatura especializada denomina el "healthy worker effect". Los trabajadores cuya salud se ve afectada de manera más grave por las malas condiciones de trabajo tienden a dejar su empleo, ya sea porque pueden hacerlo o bien porque la degradación de su estado de salud los obliga a ello. Esto explica la siguiente paradoja: en profesiones con condiciones de trabajo particularmente difíciles, los trabajadores de edad tienden a ser más saludables que sus colegas más jóvenes y que la población general del mismo grupo de edad. Son los "supervivientes".

6. En Canadá existen regímenes jurídicos distintos según las provincias y los empleos federales.

7. Dentro de este marco se adoptó en 1918, en Inglaterra, la ley "Workmen's Compensation (Silicosis) Act". 
8. Es preciso recalcar el papel importante que desempeñó la lucha de las obreras de los talleres de cerillas tanto en Francia como en Inglaterra con el fin de conseguir que se prohibiese la utilización del fósforo blanco en la producción de cerillas.

9. En un principio, este régimen de pensiones se aplicaba únicamente a los antiguos mineros que estuviesen necesitados. En 1930, el régimen se amplió para incluir también las incapacidades permanentes.

10. Los gobiernos de unión nacional eran coaliciones que se conformaban entre los 4 principales partidos que había en aquel momento: cristiano, liberal, socialista y comunista.

11. La posibilidad de recurrir a medidas de coerción con respecto a los trabajadores belgas no se excluyó, si bien no se aplicó ninguna de las soluciones propuestas. El dirigente comunista Ernest Burnelle proponía obligar a los "inciviles" (es decir, las personas que habían colaborado con los ocupantes) a trabajar en las minas y su colega socialista Achille Van Acker recomendaba recurrir al servicio militar.

12. Morelli (1988, p. 126) cita una cifra indicada por Fedechar según la cual habían sido 141.151 los mineros italianos contratados entre 1946 y 1958, si bien la autora precisa que es imposible establecer con exactitud la cifra real. Raoul Radermecker señala una cifra más baja (62.056), que se limitaba a 85 convoyes (IHOES, 1998, p. 150).

13. El sector minero, además de la CSC (confederación cristiana) y la FGTB (confederación de mayoría socialista), contaba también con un sindicato comunista que terminó uniéndose a la FGTB. Los mineros italianos más activistas se afiliaron a esta última, mientras que la mayoría, menos activa y bajo la guía de las misiones católicas, se adhirió a la CSC. Morelli cita el juicio expresado por Victor Van Laerhoven, dirigente sindical socialista en 1946: "El trabajo en las minas no es adecuado para los obreros de las regiones cálidas, donde el sol ardiente predispone a la indolencia" (1988, p. 130, traducción libre).

14. El INCA es el Istituto Nazionale Confederale di Assistenza. Se trata de un organismo creado por la Confederación sindical CGIL para asistir a los trabajadores en sus relaciones con las instituciones de la seguridad social.

15. Este sistema se mantuvo en las recomendaciones ulteriores, que contienen listas actualizadas. La última recomendación fue la de 19 de septiembre de 2003.

16. La amenaza había adquirido carácter real después de la sentencia del Tribunal de Casación dictada el 2 de febrero de 1998 confirmando una sentencia de la Magistratura de Trabajo que reconocía el trastorno lumbar de una enfermera. A pesar de esta sentencia, el FMP había mantenido una actitud intransigente de rechazo que resultó ser suficientemente disuasiva como para aligerar el pleito judicial.

17. Datos de la encuesta europea sobre las condiciones de trabajo de 2010.

18. Cámara de Representantes, $4^{a}$ sesión de la legislatura 2005-2006, doc. 51, 1334/004, 1ero de junio de 2006.

\section{RESÚMENES}

El reconocimiento de las enfermedades profesionales es un factor importante en la promoción de la prevención en los lugares de trabajo. Dicho reconocimiento fue instituido en Bélgica en 1927. Por más de 35años, la silicosis fue excluida de la lista de las enfermedades profesionales a pesar de que Bélgica tuviese una industria minera importante y que decenas de miles de mineros fuesen afectados por la silicosis. Para entender esta contradicción, es preciso analizar la historia 
social, la construcción social de los conocimientos médicos y la regulación jurídica de las enfermedades profesionales.

O reconhecimento das doenças profissionais é um fator importante na promoção da prevenção nos locais de trabalho. Este reconhecimento foi instituído na Bélgica em 1927. Durante mais de 35 anos, a silicose foi excluída da lista das doenças profissionais embora as minas de carvão constituíam um setor importante da economia e que dezenas de milhar de mineiros tinham sido afetados pela silicose. Para entender esta contradição é necessário analisar a história social, a construção social dos conhecimentos médicos e a regulação jurídica das doenças profissionais.

La reconnaissance des maladies professionnelles joue un rôle important dans l'organisation de la prévention. Cette reconnaissance a été mise en place en Belgique à partir de 1927. Pendant plus de 35 ans, la silicose a été exclue de la liste des maladies professionnelles alors que les mines de charbon constituaient un secteur important de l'économie et que des dizaines de milliers de mineurs étaient affectés par la silicose. Il faut examiner l'histoire sociale, la construction sociale des connaissances médicales et la régulation juridique des maladies professionnelles pour comprendre cette contradiction.

Compensation for occupational diseases is an important factor in promoting prevention at the workplace. This compensation was established in Belgium in 1927. For over 35 years, silicosis remained excluded from the list of occupational diseases, despite the fact that coal mines were an important sector of the economy and that dozens of thousands of miners were affected by it. To understand this contradiction we need to look into the social history, the social construction of medical knowledge and the legal regulation surrounding occupational diseases.

\section{ÍNDICE}

Keywords: occupational disease, silicosis, labor law, social history

Palabras claves: enfermedades profesionales, silicosis, derecho laboral, historia social

Palavras-chave: doenças profissionais, silicose, direito laboral, história social

Mots-clés: maladies professionnelles, silicose, droit du travail, histoire sociale

\section{AUTOR}

\section{LAURENT VOGEL}

European Trade Union Institute - ETUI, Bd du Roi Albert II, 5, 1210 Brussels, Belgium lvogel@etui.org 